\title{
Effects of a hybrid micro/nanorod topography-modified titanium implant on adhesion and osteogenic differentiation in rat bone marrow mesenchymal stem cells
}

\author{
This article was published in the following Dove Press journal: \\ International Journal of Nanomedicine \\ 10 January 2013 \\ Number of times this article has been viewed
}

\author{
Wenjie Zhang ${ }^{1,2, *}$ \\ Zihui $\mathrm{Li}^{3, *}$ \\ Qingfeng Huang' \\ Ling $\mathrm{Xu}{ }^{1}$ \\ Jinhua $\mathrm{Li}^{3}$ \\ Yuqin Jin ${ }^{1,2}$ \\ Guifang Wang ${ }^{1,2}$ \\ Xuanyong Liu ${ }^{2}$ \\ Xinquan Jiang' \\ 'Department of Prosthodontics, \\ ${ }^{2}$ Oral Bioengineering Laboratory, \\ Shanghai Research Institute of \\ Stomatology, Ninth People's Hospital \\ Affiliated to Shanghai Jiao Tong \\ University, School of Medicine, \\ ${ }^{3}$ State Key Laboratory of High \\ Performance Ceramics and Superfine \\ Microstructure, Shanghai Institute \\ of Ceramics, Chinese Academy of \\ Sciences, Shanghai, China \\ *These authors contributed equally \\ to this work
}

Correspondence: Xinquan Jiang Ninth People's Hospital, Shanghai Jiao Tong University, School of Medicine, 639 Zhizaoju Road, Shanghai, 2000 I I, China

Tel +862163135412

Fax +86 2I 63136856

Email xinquanj@yahoo.cn

Xuanyong Liu

Shanghai Institute of Ceramics, Chinese

Academy of Sciences, No 1295

Ding-xi Road, Shanghai, 200050, China

Tel +86 2l 524I2409

Fax +86 2I 524I2409

Email xyliu@mail.sic.ac.cn
Background and methods: Various methods have been used to modify titanium implant surfaces with the aim of achieving better osseointegration. In this study, we fabricated a clustered nanorod structure on an acid-etched, microstructured titanium plate surface using hydrogen peroxide. We also evaluated biofunctionalization of the hybrid micro/nanorod topography on rat bone marrow mesenchymal stem cells. Scanning electron microscopy and x-ray diffraction were used to investigate the surface topography and phase composition of the modified titanium plate. Rat bone marrow mesenchymal stem cells were cultured and seeded on the plate. The adhesion ability of the cells was then assayed by cell counting at one, 4, and 24 hours after cell seeding, and expression of adhesion-related protein integrin $\beta 1$ was detected by immunofluorescence. In addition, a polymerase chain reaction assay, alkaline phosphatase and Alizarin Red S staining assays, and osteopontin and osteocalcin immunofluorescence analyses were used to evaluate the osteogenic differentiation behavior of the cells.

Results: The hybrid micro/nanoscale texture formed on the titanium surface enhanced the initial adhesion activity of the rat bone marrow mesenchymal stem cells. Importantly, the hierarchical structure promoted osteogenic differentiation of these cells.

Conclusion: This study suggests that a hybrid micro/nanorod topography on a titanium surface fabricated by treatment with hydrogen peroxide followed by acid etching might facilitate osseointegration of a titanium implant in vivo.

Keywords: micro/nanotexture, nanorod, titanium surface, bone marrow mesenchymal stem cells, adhesion, osteogenic differentiation

\section{Introduction}

Titanium and its alloys are widely used as load-bearing implants in the clinic due to their excellent mechanical and biocompatibility properties. ${ }^{1}$ Immediately after placement of an implant into bone, proteins from the blood initially load onto the surface of the implant, then attach on the surface and participate in bone formation around the implant. ${ }^{2,3}$ During this process, the surface of the implant, being in direct contact with bone, plays a key role in determining the rate of formation as well as the quantity and quality of the bone newly formed around the implant. Therefore, osseointegration between the implant and bone could be improved by modification of the implant surface. $^{4}$

Numerous methods have been used to modify the surface of titanium, including mechanical polishing, blasting, etching, chemical treatments, oxidation, 
electropolishing, plasma spraying, and chemical vapor deposition. ${ }^{4-7}$ Among these methods, chemical treatment is a relatively simple and effective technique and has been widely investigated. ${ }^{8-11}$ In previous studies, a type of nanorod structure with a phase composition of anatase and rutile has been fabricated on a titanium surface using different chemical processes. ${ }^{12-14}$ However, biofunctionalization of the nanorod structure has not been evaluated. Because the structure of the nanorod is similar to that of hydroxyapatite crystals, we were interested in investigating the response of osteogenic cells to nanorod topography. Moreover, natural bone is a very hierarchical organized tissue, especially with regard to the extracellular matrix, which plays a major role in regulating the fate of the cell, and comprises microscale collagen fibers and nanoscale hydroxyapatite crystals. ${ }^{15}$ Accordingly, from the biomimetic viewpoint, we designed a new hierarchical hybrid micro/nanoscale texture by fabricating a clustered nanorod texture on a microstructured titanium surface formed by acid etching. Some studies have demonstrated the excellent biological properties of micro/nanostructures and their enhancement of stem cell function. ${ }^{16,17}$ As previously described, ${ }^{18-20}$ bone marrow mesenchymal stem cells (MSCs) can be recruited from the neighboring bone marrow or peripheral circulation and participate in osseointegration after implantation. In the present study, we fabricated a hybrid micro/nanorod topography with hydrogen peroxide treatment on an acid-etched titanium-6Al-4V plate surface and evaluated the effects of this hierarchical topography on the adhesion and osteogenic differentiation activity of rat bone marrow MSCs. We hope that the result of this work will improve techniques for the surface modification of endosseous titanium implants.

\section{Materials and methods} Sample preparation

Plates with dimensions of $10 \times 10 \mathrm{~mm}$ were cut from a $1 \mathrm{~mm}$ thick sheet of pure titanium (purity $>99.85 \%$, Grade 1, Baoji Shi Shenghua Nonferrous Metal Materials Co, Ltd, Baoji City, Shaanxi Province, China) and ultrasonically cleaned in $100 \%$ ethanol and deionized water. The plates were then treated with $5 \mathrm{wt} \%$ oxalic acid solution at $100^{\circ} \mathrm{C}$ for 2 hours. ${ }^{21}$ These pretreated plates with clean homogeneous microstructured surfaces were used as the control (titanium-acid) group in this study. For preparation of the experimental group (titanium-acid-hydrogen peroxide group), the pretreated plates were further incubated in $30 \mathrm{wt} \%$ hydrogen peroxide in a Teflon-lined vessel at $80^{\circ} \mathrm{C}$ for 72 hours and then dried in an ambient atmosphere for further use.

\section{Surface characterization}

Field-emission scanning electron microscopy (JEOL JSM$6700 F$, Tokyo, Japan) was used for observation of the surface morphology of the samples, with an accelerating voltage of $10 \mathrm{kV}$. Surface roughness was quantified by atomic force microscopy (SPI3800N, Seiko, Tokyo, Japan). The components on the surface of these samples were detected using a thin-film x-ray diffractometer (D/max 2500PC, Rigaku, Tokyo, Japan) with a $\mathrm{Cu} \mathrm{K \alpha}(\mathrm{k}=1.5406 \AA) \mathrm{x}$-ray source. The scans were performed from 15 to 80 degrees $2 \theta$ at 2 degrees per minute, with a scanning step of 0.02 and 2 degree glancing angles for the incident beam against the surface of the specimens. The elemental composition of the sample surfaces was determined by x-ray photoelectron spectroscopy (PHI 5802 system, Physical Electronics Inc, Eden Prairie, MN) with a $\mathrm{Mg} \mathrm{K \alpha}(1253.6 \mathrm{eV})$ source.

\section{Culture of rat bone marrow MSCs}

Bone marrow MSCs were isolated and cultured from 6-weekold male F344 rats according to our previously published procedures. ${ }^{22}$ Briefly, the bone marrow was rinsed using Dulbecco's modified Eagle's medium (Gibco BRL, Grand Island, NY) with 10\% fetal bovine serum (Hyclone, Logan, UT) and $200 \mathrm{U} / \mathrm{mL}$ heparin (Sigma, St Louis, MO) from rat femurs after both ends were cut off at the epiphysis. Cells were cultured in Dulbecco's modified Eagle's medium with $10 \%$ fetal bovine serum in an incubator with an atmosphere of $5 \% \mathrm{CO}_{2}$ at $37^{\circ} \mathrm{C}$. Nonadherent cells were removed by the first medium change after 24 hours. Cells at passage 2-3 were used in this study.

\section{Cell proliferation activity assay}

The MTT cell metabolic assay (Sigma) was used to evaluate the cell proliferation activity of the bone marrow MSCs on the two different substrates. ${ }^{23,24}$ Initially, $2.0 \times 10^{4}$ cells per $\mathrm{mL}$ were plated onto each sample in a 24-well plate. After one, 4 , and 7 days of culture, the MTT solution was added into the targeted wells, and the specimens were incubated for 3 hours to form formazan. The formazan was dissolved in dimethyl sulfoxide and measured at $490 \mathrm{~nm}$ using an ELX ultra microplate reader (BioTek, Winooski, VT). The experiment was performed in triplicate.

\section{Reverse transcription and real-time PCR assay}

Initially, $2.0 \times 10^{4}$ cells/well were seeded on titanium plates in 24-well plates. After 14 days of culture in Dulbecco's modified Eagle's medium, the total RNA from cells on the 
titanium and nanorod substrates was extracted with TRIzol reagent (Invitrogen, Grand Island, NJ), and the cDNA was generated using a PrimeScript 1st strand cDNA synthesis kit (TaKaRa, Shiga, Japan). The expression of fibronectin, integrin $\alpha 1$ and integrin $\beta 1$, Runx-2, alkaline phosphatase, osteopontin, and osteocalcin in the two groups was measured using reverse transcription polymerase chain reaction (RTPCR), with 30 cycles of denaturation at $95^{\circ} \mathrm{C}$ for 30 seconds, annealing at $58^{\circ} \mathrm{C}$ for 30 seconds, and elongation at $72^{\circ} \mathrm{C}$ for 30 seconds. The amplification products were examined by $2.0 \%$ agarose gel electrophoresis. The RT-PCR results were further confirmed using a real-time PCR system (Bio-Rad, Hercules, CA). The housekeeping gene, GAPDH, was used for normalization. ${ }^{25,26}$ The specific primer sequences used in this study are listed in Table 1.

\section{Cell adhesion ability assay}

Cell counts at the initial seeding period (one, 4, and 24 hours) were taken to represent the adhesive cells on the different samples. ${ }^{23}$ Cells at a density of $5.0 \times 10^{4}$ cells/well were seeded on the different titanium plates in 24 -well plates. At each time point, the nonadherent cells were rinsed and removed by phosphate-buffered solution. For fluorescence staining, the cells remaining on the plates were fixed with $4 \%$ paraformaldehyde for 30 minutes at $4^{\circ} \mathrm{C}$. After the cell nuclei were stained using DAPI (Invitrogen), the samples were observed under a confocal laser scanning microscope (Leica, Hamburg, Germany). For counting the number of cells attached, five samples for each group were detected at each time point. The cells were detached with trypsin-EDTA solution ( $0.25 \%$ trypsin with $1 \mathrm{mM}$ EDTA) and analyzed using a FACSCalibur flow cytometry system (Becton Dickinson, Franklin Lakes, NJ).

To detect the expression of cell-adhesion-related protein, integrin $\beta 1$, in the different samples, cells at a density of $1.0 \times 10^{4}$ cells/well were seeded on the different titanium plates in 24-well plates. Four hours later, the cells were fixed with $4 \%$ paraformaldehyde and treated with $1 \%$ Triton X-100 for 30 minutes at room temperature. After blocking in $10 \%$ goat serum for one hour at room temperature, a specific primary antibody targeting integrin $\beta 1$ (Abcam, Cambridge, MA) and a FITC-phalloidin antibody (Enzo Life Sciences, Exeter, UK) were added and incubated overnight at $4^{\circ} \mathrm{C}$. Next, a DyLight 549-conjugated anti-mouse IgG antibody (Invitrogen) was used for one hour at $37^{\circ} \mathrm{C}$ in the dark. Nuclei were stained with DAPI for 5 minutes, and the samples were then observed using the confocal laser scanning microscope.

\section{Alkaline phosphatase activity and calcium deposition assay}

Initially, $2.0 \times 10^{4}$ cells/well were seeded on the different titanium plates in 24-well plates. After 14 days of incubation in Dulbecco's modified Eagle's medium, the cells were fixed and stained using an alkaline phosphatase kit (Shanghai Hongqiao Medical Reagent Company, Shanghai, China) and 0.1\% Alizarin Red S solution for alkaline phosphatase staining and Alizarin Red S staining, respectively. ${ }^{26,27}$ A semiquantitative analysis of alkaline phosphatase and calcium deposition was performed as previously described. ${ }^{25}$ Alkaline phosphatase activity was determined by measuring the OD values for absorbance at $405 \mathrm{~nm}$ after incubation with p-nitrophenyl

Table I Primers for real-time and reverse transcriptase polymerase chain reaction

\begin{tabular}{|c|c|c|c|}
\hline Gene & Prime sequence ( $F$, forward; $R$, reverse) & Product size (bp) & Accession number \\
\hline \multirow[t]{2}{*}{ GAPDH } & F: GGCAAGTTCAACGGCACAGT & 76 & NM_0I7008.3 \\
\hline & R: GCCAGTAGACTCCACGACAT & & \\
\hline \multirow[t]{2}{*}{ Fibronectin } & F: CCTTAAGCCTTCTGCTCTGG & 301 & NM_019143.2 \\
\hline & R: CGGCAAAAGAAAGCAGAACT & & \\
\hline \multirow[t]{2}{*}{ Integrin $\alpha$ | } & F: AGCTGGACATAGTCATCGTC & 374 & NM_030994.I \\
\hline & R: AGTTGTCATGCGATTCTCCG & & \\
\hline \multirow[t]{2}{*}{ Integrin $\beta$ I } & F: AATGTTTCAGTGCAGAGCC & 262 & NM_0I7022.I \\
\hline & R: TTGGGATGATGTCGGGAC & & \\
\hline \multirow[t]{2}{*}{ Runx-2 } & F: TCTTCCCAAAGCCAGAGCG & 154 & NM_053470.I \\
\hline & R: TGCCATTCGAGGTGGTCG & & \\
\hline \multirow[t]{2}{*}{ ALP } & F: GTCCCACAAGAGCCCACAAT & 172 & NM_0I3059.I \\
\hline & R: CAACGGCAGAGCCAGGAAT & & \\
\hline \multirow[t]{2}{*}{ OPN } & F: TGGATGAACCAAGCGTGGA & 168 & NM_0I288I.2 \\
\hline & R: TCGCCTGACTGTCGATAGCA & & \\
\hline \multirow[t]{2}{*}{$\mathrm{OCN}$} & F: CAGTAAGGTGGTGAATAGACTCCG & 172 & NM_0I34I4.I \\
\hline & R: GGTGCCATAGATGCGCTTG & & \\
\hline
\end{tabular}

Abbreviations: ALP, alkaline phosphatase; OPN, osteopontin; OCN, osteocalcin. 
phosphate (Sigma) for 30 minutes at $37^{\circ} \mathrm{C}$. For quantification of Alizarin Red S, the stained samples were desorbed using $10 \%$ cetylpyridinium chloride (Sigma), and the OD values for absorbance of the eluent were determined at $590 \mathrm{~nm}$. Total protein values were measured using the Bio-Rad protein assay kit at $630 \mathrm{~nm}$. The results of the alkaline phosphatase and calcium deposition quantity analyses were normalized and presented as OD values per mg of total protein.

\section{Immunofluorescence of osteopontin and osteocalcin}

Initially, $2.0 \times 10^{4}$ cells per well were seeded and cultured in Dulbecco's modified Eagle's medium for 14 days. The cells were fixed in 4\% paraformaldehyde for 30 minutes at $4{ }^{\circ} \mathrm{C}$ and treated with $1 \%$ Triton $\mathrm{X}-100$ for 30 minutes at room temperature. After being blocked with $3 \%$ bovine serum albumin, the samples were incubated in specific rat primary antibodies against osteocalcin (Abcam) and osteopontin (Abcam) overnight at $4^{\circ} \mathrm{C}$. Additionally, the cellular cytoskeleton was stained with FITC-phalloidin. The samples were then incubated with a red fluorescently labeled goat antimouse secondary antibody for another 30 minutes at $37^{\circ} \mathrm{C}$. After the nuclei were stained with DAPI, the specimens were observed using the confocal laser-scanning microscope.

\section{Statistical analysis}

The data were expressed as the mean \pm standard deviation and analyzed using the $t$-test. The significance level for the statistical analysis was set at $P<0.05$.

\section{Results and discussion Sample characterization}

The surface morphology of the two samples was detected by field-emission scanning electron microscopy (Figure 1). On the titanium-acid plate surface, microscale edges were observed at a low magnification of $5000 \times$, which was the

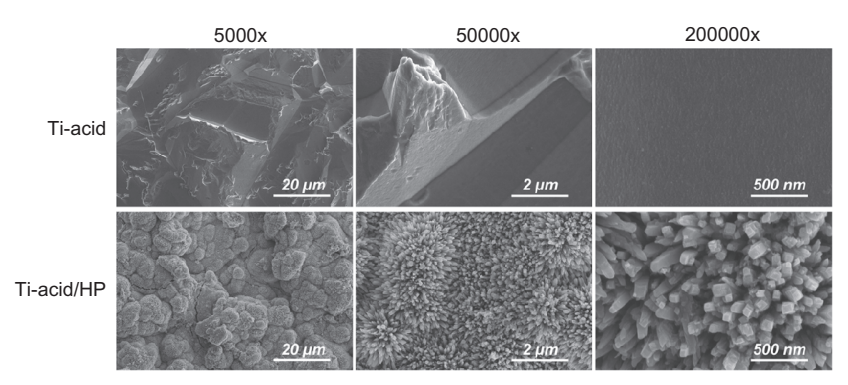

Figure I Scanning electron microscopic images of two titanium surfaces at various magnification.

Abbreviations: Ti, titanium; HP, hydrogen peroxide. result of pickling by oxalic acid solution. However, under a higher magnification of $200,000 \times$, the topography appeared flat. Thin-film x-ray diffraction (pattern of the control sample) only exhibited the characteristic peaks of titanium, indicating that the surface oxidation layer was almost removed after pickling (Figure 2). Pickling in oxalic acid is a method commonly used to pretreat titanium because it can produce samples with microscale surfaces and multifaceted devices with complex three-dimensional shapes, making them superior for practical application. Moreover, this method has been used to treat orthopedic and dental implants because it has the ability to induce distinct osteoblastic functions in vitro ${ }^{28}$ and enhance the bone-implant contact. ${ }^{29}$ Based on the pretreated microstructures, we fabricated a nanorod structure using hydrothermal hydrogen peroxide treatment. At a low magnification of $5000 \times$, the sharp microscale edges on the titanium-acid-hydrogen peroxide plate surface were smoother and the uneven surface was paved with more clustered nanorod structures than the titanium-acid group. Under higher magnification, uniform hydroxyapatite-like nanorod structures were observed. Moreover, as shown in Table 2, the surface roughness of the titanium-acid-hydrogen peroxide plate was obviously greater than that of the titanium-acid sample $(P<0.05)$. For detection of the surface composition, characteristic peaks of crystalline anatase and rutile appeared in the thin film x-ray diffraction pattern, indicating that the nanorod structure-modified surface was composed of crystalline titanium (Figure 2). A detailed surface atomic composition analysis was also performed using the x-ray photoelectron spectroscopy method (Figure 3), which demonstrated that the basic components of the titanium-acid and titaniumacid-hydrogen peroxide sample surfaces are consistent. Only titanium and oxygen were detected on the surfaces of both

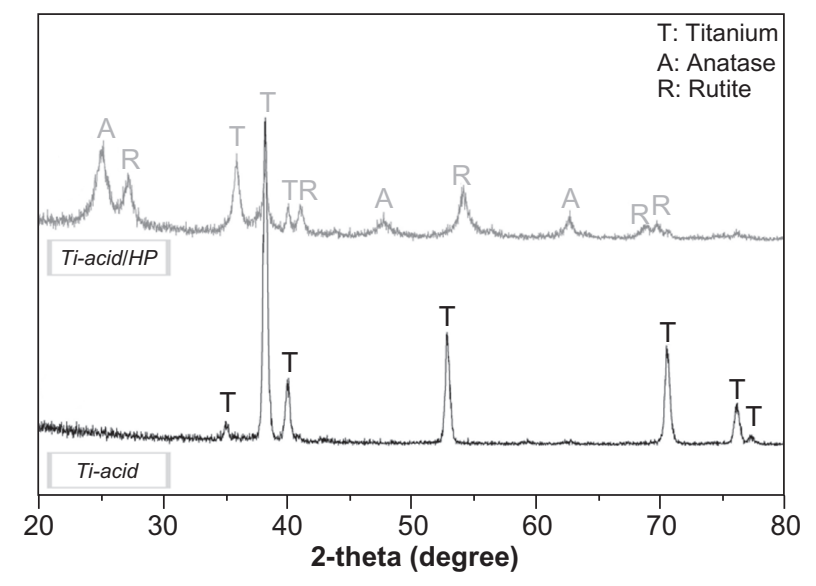

Figure $2 \mathrm{X}$-ray diffraction patterns for various titanium surfaces. Abbreviations: Ti, titanium; HP, hydrogen peroxide. 
Table 2 Average surface roughness values for the acid and titaniumacid-hydrogen peroxide-treated surfaces used in this study

\begin{tabular}{lc}
\hline Surface & $\mathbf{R a}(\mathbf{n m})$ \\
\hline Titanium-acid & $64.41 \pm 5.86$ \\
Titanium-acid-hydrogen peroxide & $167.22 \pm 15.28 *$ \\
\hline
\end{tabular}

Notes: Data are expressed as the mean \pm standard deviation, $n=6$ per group. $* P<0.05$ versus the titanium-acid group.

Abbreviation: $\mathrm{Ra}$, surface roughness.

samples, and the oxygen on the titanium-acid sample originated from the natural oxide layer on its surface.

\section{Cell adhesion activity}

It is widely accepted in clinical implant medicine that formation of a direct interface between an endosseous implant and new bone produced by bone marrow MSCs occurs during the osseointegration process. Bone marrow MSCs can be recruited from neighboring bone marrow or the peripheral circulation and participate in osseointegration after implantation. For the bone marrow MSCs that participate in the osseointegration process, cell adhesion on the material
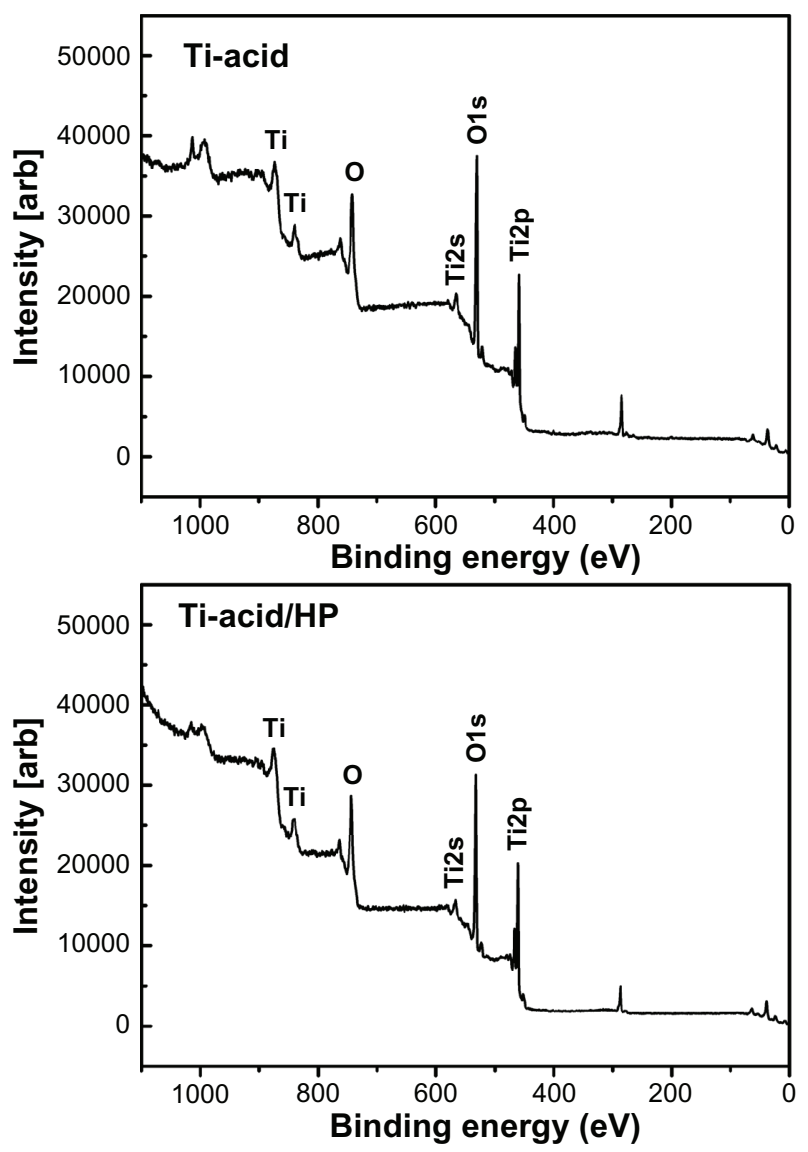

Figure 3 Full $x$-ray photoelectron spectra of titanium-acid and titanium-acidhydrogen peroxide surfaces.

Abbreviations: Ti, titanium; HP, hydrogen peroxide. surface is the initial step for cell-material interactions, and deficient adhesion may affect subsequent cell osteogenic differentiation activity.

It is well known that cell adhesion occurs through binding of integrins, which are receptors that adhere specifically to matrix proteins such as fibronectin and various collagens. ${ }^{30}$ In the present study, we detected expression of integrin $\alpha 1$, integrin $\beta 1$, and fibronectin genes in cells seeded on the different substrates by PCR assay, with the resulting data shown in Figure 4. In the titanium-acid-hydrogen peroxide group, expression levels of all three genes were upregulated by the hybrid micro/nanotextured topography. Interactions between integrin receptors and extracellular matrix proteins not only provide cells with a physical link to the extracellular matrix but also serve as a channel for propagating signals from the extracellular environment.

To confirm the adhesion activity further, cells attached onto both titanium-acid and titanium-acid-hydrogen peroxide plates were detected after rinsing with phosphate-buffered solution at one, 4, and 24 hours (Figure 5A). Figure 5B shows the results of cell counting. The number of adherent cells on the micro/nanorod-modified surface was more than

A Real time PCR

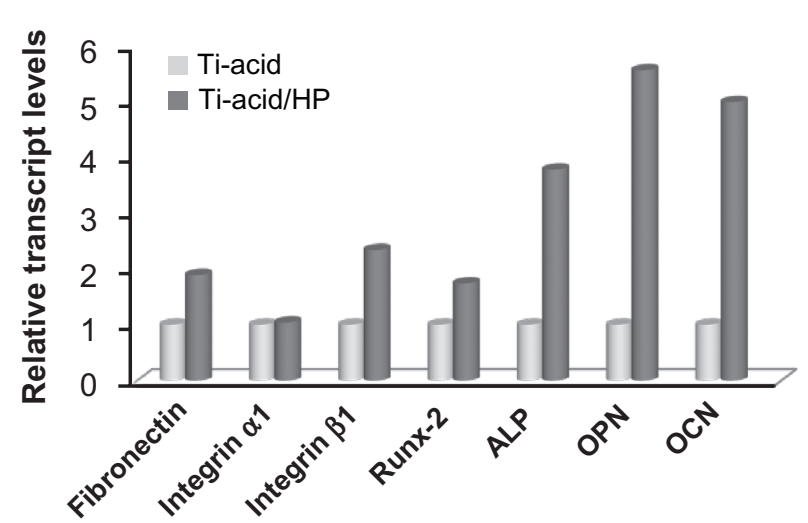

B

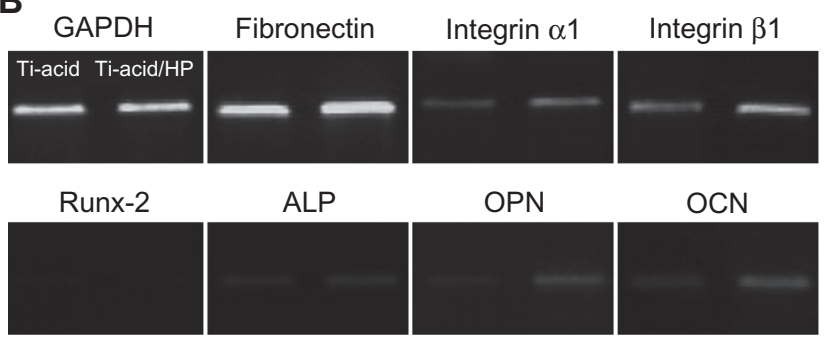

Figure 4 Real-time polymerase chain reaction. (A) After 14 days' incubation, expression of adhesion-related genes (fibronectin, integrin $\alpha I$, and integrin $\beta I$ ) and osteogenic differentiation-related genes (Runx-2, ALP, OPN, and OCN) was measured by real-time polymerase chain reaction. (B) Reaction products of reverse transcriptase PCR were further examined by $2.0 \%$ agarose gel electrophoresis. Abbreviations: Ti, titanium; HP, hydrogen peroxide; PCR, polymerase chain reaction; ALP, alkaline phosphatase; OPN, osteopontin; OCN, osteocalcin. 

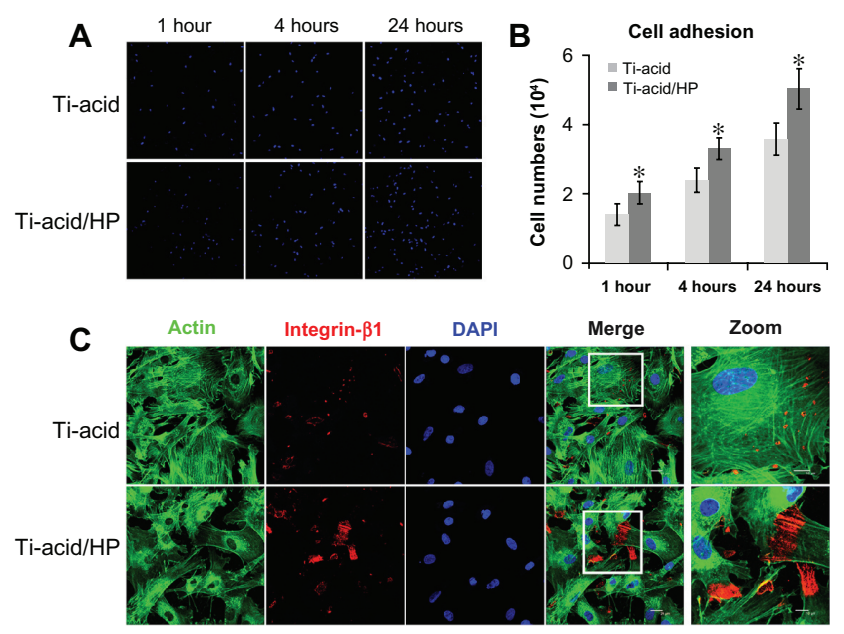

Figure 5 Cell adhesion assay. (A) Cell nuclei stained with DAPI were imaged by confocal laser scanning microscopy for the two groups at one, 4, and 24 hours after seeding. (B) Statistical results for adhesive cell numbers. (C) Expression of integrin $\beta \mathrm{I}$ was detected by confocal laser scanning microscopy.

Notes: Green color, actin cytoskeleton of bone marrow mesenchymal stem cells stained with FITC-phalloidin; red color, integrin $\beta \mathrm{I}$ of bone marrow mesenchymal stem cells stained with DyLight 549; blue color, nuclei of bone marrow mesenchymal stem cells stained with DAPI. $* P<0.05$ versus titanium-acid group. Abbreviations: $\mathrm{Ti}$, titanium; HP, hydrogen peroxide.

in the titanium-acid group at all three time points $(P<0.05)$. In addition, expression of integrin $\beta 1$ at 4 hours is shown in Figure 5C, and the cells seeded on the titanium-acid-hydrogen peroxide plate expressed a higher level of integrin $\beta 1$. Enhancement of cell adhesion by various nanotextures or micro/nanotextures has been widely reported. ${ }^{16,23,31-33}$ However, the exact effect of nanotextures on cell adhesion activity remains to be determined. ${ }^{34}$ One possible explanation is that the high surface energy of the sharp ridges in the nanoscale range facilitates formation of focal adhesions. ${ }^{35-37}$ In addition, similar to what $\mathrm{Oh}$ et al have indicated, ${ }^{35}$ when immersed in culture medium containing serum, proteins including bovine serum albumin, fibronectin, and albumin, load onto the available top portion of a nanotube wall early on during incubation, and further deposits of serum proteins on the implant surface may promote initial adhesion of cells, as previously reported. ${ }^{38,39}$ In the present study, the increased surface area created by micro/nanorod topography modification might enhance the persistence of serum proteins.

\section{Cell metabolism and proliferation activity}

The results of the MTT cell metabolic activity assay are shown in Figure 6. There were no statistically significant differences between the two samples at day 1 and day 4. However, at day 7 , total cell metabolic activity on the micro/nanorod structure was significantly greater than that on the control surface. The metabolic situation of individual cells and cell numbers

\section{MTT results}

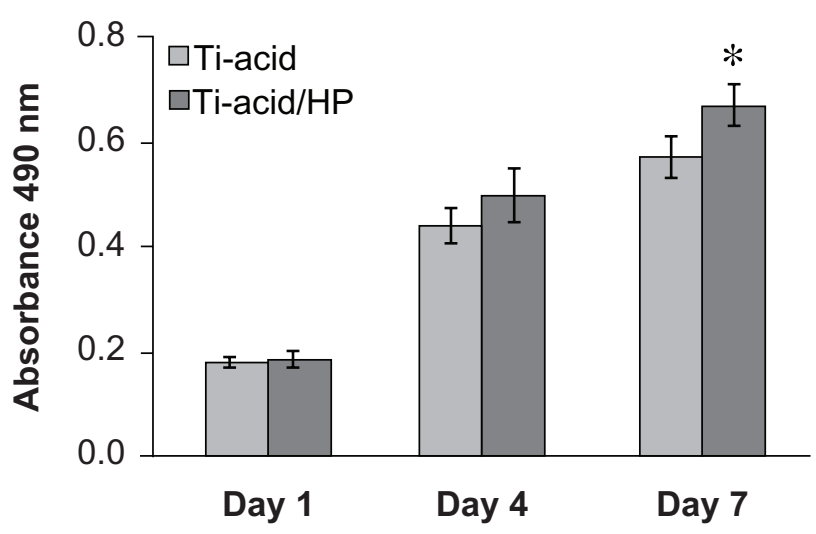

Figure 6 Analysis of cell metabolism.

Note: $* P<0.05$, when compared with the titanium-acid group.

Abbreviations: Ti, titanium; HP, hydrogen peroxide.

both contribute to total cell metabolic activity. In this study, upregulation of cellular metabolism was most likely created by increasing cell numbers. The ability of nanotopography to promote cell proliferation has been confirmed. ${ }^{15,40}$ Increased initial adhesion of cells likely also promotes cell proliferation activity on the titanium-acid-hydrogen peroxide plate.

\section{Osteogenic differentiation activity in bone marrow MSCs}

As shown in Figure 4, expression of several osteogenic differentiation-related genes, including the early markers Runx-2 and $A L P$, the medium-stage marker $O P N$, and late-stage marker $O C N$, was detected by PCR assay. All of these mRNAs were upregulated after 14 days of culture on the micro/nanorod topography-modified titanium surface, especially expression of markers related to late osteogenic differentiation, ie, $O P N$ and $O C N$. Furthermore, the alkaline phosphatase activity assay, calcium deposition assay, and osteopontin/osteocalcin immunofluorescence were performed to confirm further osteogenic differentiation activity in rat bone marrow MSCs. For the alkaline phosphatase activity assay, more pronounced alkaline phosphatase-positive areas were observed on the micro/nanorod structures than on the controls (Figure 7A), and cells on the hybrid micro/nanoscale texturemodified surface expressed more alkaline phosphatase activity according to the quantification results ( $P<0.05$, Figure 7B). Similar results were demonstrated by Alizarin Red $\mathrm{S}$ staining (Figure 7A) and quantitative calculation using the calcium deposition assay (Figure 7C). The alkaline phosphatase and calcium deposition assays are commonly used to evaluate osteogenic differentiation in various cells. Our results indicate 

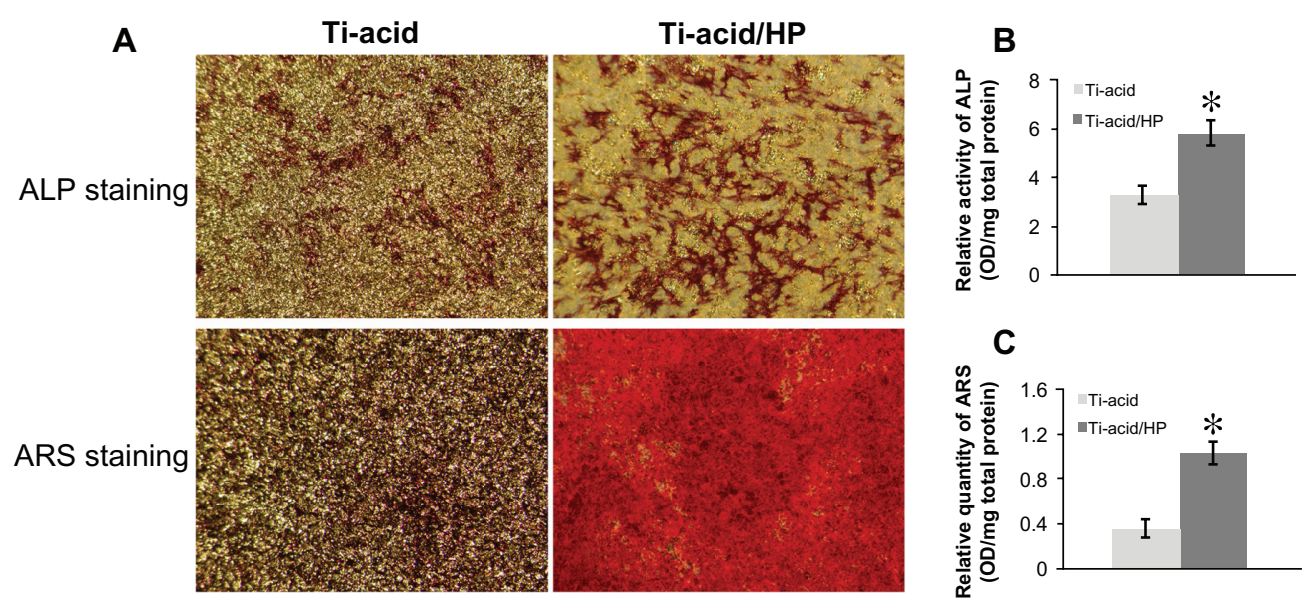

Figure 7 Alkaline phosphatase activity and calcium deposition assay. (A) After I4 days culture, bone marrow mesenchymal stem cells on the various titanium surfaces were stained with an alkaline phosphatase kit and Alizarin Red S solution. (B) Alkaline phosphatase activity of bone marrow mesenchymal stem cells was measured with quantitative assay. (C) Calcium deposition status of cells was assayed using colorimetrically quantitative analysis.

Note: ${ }^{*} P<0.05$ versus titanium-acid group.

Abbreviations: Ti, titanium; HP, hydrogen peroxide; ALP, alkaline phosphatase; ARS, Alizarin Red S.

that osteogenic differentiation of rat bone marrow MSCs was promoted by micro/nanorod topography. As shown in Figure 8, expression of osteopontin and osteocalcin was further detected at the protein level using an immunofluorescence method, and the cells seeded on the titanium-acid-hydrogen peroxide plate expressed a higher level of both proteins.

Taken together, our results clearly demonstrate that the micro/nanorod topography-modified titanium surface was beneficial for promoting osteogenic differentiation of rat bone
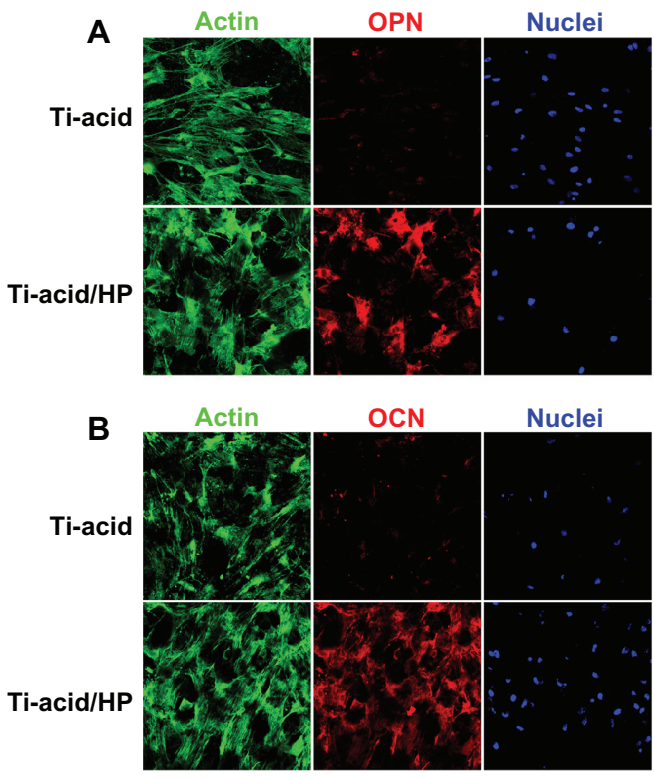

Figure 8 Detection of osteopontin/osteocalcin immunofluorescence.

Notes: After a 14-day incubation period in Dulbecco's modified Eagle's medium, osteopontin and osteocalcin immunofluorescence results were observed by confocal laser scanning microscope. Green, actin cytoskeleton; blue, nuclei; red, osteopontin/osteocalcin positive area; and yellow, merged color of green and red. Scale bar $100 \mu \mathrm{m}$. marrow MSCs. As discussed above, the micro/nanorod texture facilitated cell adhesion, which increased the number of contact spots between cells and the matrix. These spots play a key role in cell signal transduction of external stimuli. The focal adhesion kinase/extracellular signal-regulated kinase signaling pathway is well known to be related to osteogenic differentiation activity in cells. ${ }^{41,42}$ Many studies have shown that nanotopographies dictate the differentiation activity of stem cells by influencing the phosphorylation of these two kinases. ${ }^{43,44}$ Recent work has also demonstrated that the integrin-linked kinase $/ \beta$-catenin pathway is important in mediating signals from topographical cues to direct osteogenic differentiation of cells. ${ }^{45}$ The exact role of hybrid micro/nanorod topography in the response of the cell remains to be determined.

\section{Conclusion}

In this study, a clustered nanorod topography on an acidetched microtextured titanium surface was produced by treatment with hydrogen peroxide treatment for 72 hours. The hierarchical hybrid micro/nanoscale texture-modified titanium surface facilitated the initial adhesion activity of rat bone marrow MSCs. Importantly, the osteogenic differentiation activity of these cells was also obviously promoted by the modified surface. The enhanced adhesion and osteogenic differentiation abilities of the rat bone marrow MSCs on the titanium-acid-hydrogen peroxide plates suggest the potential to improve bone-titanium integration in vivo.

\section{Acknowledgments}

This work was jointly supported by the National Basic Research Program of China (973 Program, 2012CB933604, 
and 2012CB933601), the National Science Fund for Distinguished Young Scholars of China (81225006), the National Natural Science Foundation of China (51071168, 81170939, and 30973342) and the Science and Technology Commission of Shanghai Municipality (S30206, 10430710900, and 10dz2211600).

\section{Disclosure}

The authors report no conflicts of interest in this work.

\section{References}

1. Wisbey A, Gregson P, Peter LM, Tuke M. Effect of surface treatment on the dissolution of titanium-based implant materials. Biomaterials. 1991;12(5):470-473.

2. Junker R, Dimakis A, Thoneick M, Jansen JA. Effects of implant surface coatings and composition on bone integration: a systematic review. Clin Oral Implants Res. 2009;20 Suppl 4:185-206.

3. Lemons JE. Biomaterials, biomechanics, tissue healing, and immediatefunction dental implants. J Oral Implantol. 2004;30(5):318-324.

4. Wennerberg A, Albrektsson T. Effects of titanium surface topography on bone integration: a systematic review. Clin Oral Implants Res. 2009; 20 Suppl 4:172-184.

5. Liu X, Chu PK, Ding C. Surface nano-functionalization of biomaterials. Mater Sci Eng R Rep. 2010;70(3):275-302.

6. Wang H, Eliaz N, Xiang Z, Hsu HP, Spector M, Hobbs LW. Early bone apposition in vivo on plasma-sprayed and electrochemically deposited hydroxyapatite coatings on titanium alloy. Biomaterials. 2006;27(23):4192-4203.

7. Brama M, Rhodes N, Hunt J, et al. Effect of titanium carbide coating on the osseointegration response in vitro and in vivo. Biomaterials. 2007;28(4):595-608.

8. Wang XX, Hayakawa S, Tsuru K, Osaka A. A comparative study of in vitro apatite deposition on heat-, $\mathrm{H}(2) \mathrm{O}(2)$-, and $\mathrm{NaOH}$-treated titanium surfaces. J Biomed Mater Res. 2001;54(2):172-178.

9. Shi GS, Ren LF, Wang LZ, Lin HS, Wang SB, Tong YQ. $\mathrm{H}_{2} \mathrm{O}_{2} / \mathrm{HCl}$ and heat-treated Ti-6Al-4V stimulates pre-osteoblast proliferation and differentiation. Oral Surg Oral Med Oral Pathol Oral Radiol Endod. 2009;108(3):368-375.

10. Wang XX, Hayakawa S, Tsuru K, Osaka A. Improvement of bioactivity of $\mathrm{H}(2) \mathrm{O}(2) / \mathrm{TaCl}(5)$-treated titanium after subsequent heat treatments. J Biomed Mater Res. 2000;52(1):171-176.

11. Kaneko S, Tsuru K, Hayakawa S, et al. In vivo evaluation of bonebonding of titanium metal chemically treated with a hydrogen peroxide solution containing tantalum chloride. Biomaterials. 2001;22(9): 875-881.

12. Zhang H, Liu P, Liu, X et al. Fabrication of highly ordered $\mathrm{TiO}_{2}$ nanorod/ nanotube adjacent arrays for photoelectrochemical applications. Langmuir. 2010;26(13):11226-11232.

13. Wu JM, Zhang TW, Zeng YW, Hayakawa S, Tsuru K, Osaka A. Large-scale preparation of ordered titania nanorods with enhanced photocatalytic activity. Langmuir. 2005;21(15):6995-7002.

14. Joo J, Kwon SG, Yu T, et al. Large-scale synthesis of $\mathrm{TiO} 2$ nanorods via nonhydrolytic sol-gel ester elimination reaction and their application to photocatalytic inactivation of E. coli. J Phys Chem B. 2005;109(32): 15297-15302.

15. Stevens MM, George JH. Exploring and engineering the cell surface interface. Science. 2005;310(5751):1135-1138.

16. Zhao L, Mei S, Chu PK, Zhang Y, Wu Z. The influence of hierarchical hybrid micro/nano-textured titanium surface with titania nanotubes on osteoblast functions. Biomaterials. 2010;31(19):5072-5082.

17. Kubo K, Tsukimura N, Iwasa F, et al. Cellular behavior on $\mathrm{TiO}_{2}$ nanonodular structures in a micro-to-nanoscale hierarchy model. Biomaterials. 2009;30(29):5319-5329.
18. Xu B, Zhang J, Brewer E, et al. Osterix enhances BMSC-associated osseointegration of implants. J Dent Res. 2009;88(11):1003-1007.

19. Fuerst G, Gruber R, Tangl S, Sanroman F, Watzek G. Enhanced boneto-implant contact by platelet-released growth factors in mandibular cortical bone: a histomorphometric study in minipigs. Int $J$ Oral Maxillofac Implants. 2003;18(5):685-690.

20. Schneider GB, Zaharias R, Seabold D, Keller J, Stanford C. Differentiation of preosteoblasts is affected by implant surface microtopographies. J Biomed Mater Res A. 2004;69(3):462-468.

21. Wu Y, Long M, Cai W, et al. Preparation of photocatalytic anatase nanowire films by in situ oxidation of titanium plate. Nanotechnology. 2009;20(18):185703.

22. Jiang X, Zhao J, Wang S, et al. Mandibular repair in rats with premineralized silk scaffolds and BMP-2-modified bMSCs. Biomaterials. 2009;30(27):4522-4532.

23. Zhao L, Mei S, Chu PK, Zhang Y, Wu Z. The influence of hierarchical hybrid micro/nano-textured titanium surface with titania nanotubes on osteoblast functions. Biomaterials. 2010;31(19):5072-5082.

24. Cruz T, Gaspar R, Donato A, Lopes C. Interaction between polyalkylcyanoacrylate nanoparticles and peritoneal macrophages: MTT metabolism, NBT reduction, and NO production. Pharm Res. 1997;14(1):73-79.

25. Zou D, Han W, You S, et al. In vitro study of enhanced osteogenesis induced by HIF-1alpha-transduced bone marrow stem cells. Cell Prolif. 2011;44(3):234-243.

26. Wang S, Zhang Z, Zhao J, et al. Vertical alveolar ridge augmentation with beta-tricalcium phosphate and autologous osteoblasts in canine mandible. Biomaterials. 2009;30(13):2489-2498.

27. Kaur G, Wang C, Sun J, Wang Q. The synergistic effects of multivalent ligand display and nanotopography on osteogenic differentiation of rat bone marrow stem cells. Biomaterials. 2010;31(22):5813-5824.

28. Takeuchi K, Saruwatari L, Nakamura HK, Yang JM, Ogawa T. Enhanced intrinsic biomechanical properties of osteoblastic mineralized tissue on roughened titanium surface. J Biomed Mater Res A. 2005; 72(3):296-305.

29. Ogawa T, Nishimura I. Different bone integration profiles of turned and acid-etched implants associated with modulated expression of extracellular matrix genes. Int J Oral Maxillofac Implants. 2003;18(2): 200-210.

30. Hynes RO. Integrins: a family of cell surface receptors. Cell. 1987; 48(4):549-554.

31. Zaveri TD, Dolgova NV, Chu BH, et al. Contributions of surface topography and cytotoxicity to the macrophage response to zinc oxide nanorods. Biomaterials. 2010;31(11):2999-3007.

32. Park J, Bauer S, von der Mark K, Schmuki P. Nanosize and vitality: TiO, nanotube diameter directs cell fate. Nano Lett. 2007;7(6):1686-1691.

33. Sjostrom T, Dalby MJ, Hart A, Tare R, Oreffo RO, Su B. Fabrication of pillar-like titania nanostructures on titanium and their interactions with human skeletal stem cells. Acta Biomater. 2009;5(5):1433-1441.

34. Zhang W, Li Z, Liu Y, et al. Biofunctionalization of a titanium surface with a nano-sawtooth structure regulates the behavior of rat bone marrow mesenchymal stem cells. Int J Nanomedicine. 2012;7:4459-4472.

35. Oh S, Brammer KS, Li YS, et al. Stem cell fate dictated solely by altered nanotube dimension. Proc Natl Acad Sci U S A. 2009;106(7): 2130-2135.

36. Luthen F, Lange R, Becker P, Rychly J, Beck U, Nebe JG. The influence of surface roughness of titanium on beta1- and beta3-integrin adhesion and the organization of fibronectin in human osteoblastic cells. Biomaterials. 2005;26(15):2423-2440.

37. Diener A, Nebe B, Luthen F, et al. Control of focal adhesion dynamics by material surface characteristics. Biomaterials. 2005;26(4):383-392.

38. Mendonca G, Mendonca DB, Aragao FJ, Cooper LF. Advancing dental implant surface technology - from micron- to nanotopography. Biomaterials. 2008;29(28):3822-3835.

39. Deligianni DD, Katsala N, Ladas S, Sotiropoulou D, Amedee J, Missirlis YF. Effect of surface roughness of the titanium alloy Ti-6Al-4V on human bone marrow cell response and on protein adsorption. Biomaterials. 2001;22(11):1241-1251. 
40. Peng L, Eltgroth ML, LaTempa TJ, Grimes CA, Desai TA. The effect of $\mathrm{TiO}_{2}$ nanotubes on endothelial function and smooth muscle proliferation. Biomaterials. 2009;30(7):1268-1272.

41. Salasznyk RM, Klees RF, Boskey A, Plopper GE. Activation of FAK is necessary for the osteogenic differentiation of human mesenchymal stem cells on laminin-5. J Cell Biochem. 2007;100(2):499-514.

42. Salasznyk RM, Klees RF, Williams WA, Boskey A, Plopper GE. Focal adhesion kinase signaling pathways regulate the osteogenic differentiation of human mesenchymal stem cells. Exp Cell Res. 2007; 313(1):22-37.
43. Biggs MJP, Richards RG, Dalby MJ. Nanotopographical modification: a regulator of cellular function through focal adhesions. Nanomedicine (Lond). 2010;6(5):619-633.

44. Kantawong F, Burgess KEV, Jayawardena K, et al. Whole proteome analysis of osteoprogenitor differentiation induced by disordered nanotopography and mediated by ERK signalling. Biomaterials. 2009; 30(27):4723-4731.

45. Wang W, Zhao L, Wu K, et al. The role of integrin-linked kinase/ $\beta$ catenin pathway in the enhanced MG63 differentiation by micro/ nano-textured topography. Biomaterials. 2013;34(3):631-640.
International Journal of Nanomedicine

\section{Publish your work in this journal}

The International Journal of Nanomedicine is an international, peerreviewed journal focusing on the application of nanotechnology in diagnostics, therapeutics, and drug delivery systems throughout the biomedical field. This journal is indexed on PubMed Central, MedLine, CAS, SciSearch $®$, Current Contents $® /$ Clinical Medicine,

\section{Dovepress}

Journal Citation Reports/Science Edition, EMBase, Scopus and the Elsevier Bibliographic databases. The manuscript management system is completely online and includes a very quick and fair peer-review system, which is all easy to use. Visit http://www.dovepress.com/ testimonials.php to read real quotes from published authors.

Submit your manuscript here: http://www.dovepress.com/international-journal-of-nanomedicine-journal 